\title{
Visceral Surgery: Treatment Options in Palliative Care
}

\section{Nader El-Sourani ${ }^{1^{*}}$, Achim Troja ${ }^{1}$, Pietro Contin ${ }^{2}$, Hans-Rudolf Raab ${ }^{1}$ and Dalibor Antolovic ${ }^{1}$}

${ }^{1}$ Klinikum Oldenburg, General-and Visceral Surgery, Germany

${ }^{2}$ Universtitäts Klinikum Heidelberg, General-and Visceral Surgery, Germany

*Corresponding author: Nader El-Sourani, General-and Visceral Surgery, Klinikum Oldenburg, Rahel-Straus-Str. 10, Germany, Tel: 0049-441-403-77628; E-mail: nader@elsourani.com

\section{Rec date: Mar 10, 2014, Acc date: May 15, 2014, Pub date: June 1, 2014}

Copyright: (C) 2014 El-Sourani $\mathrm{N}$ et al. This is an open-access article distributed under the terms of the Creative Commons Attribution License, which permits unrestricted use, distribution, and reproduction in any medium, provided the original author and source are credited.

\author{
Abstract \\ Background: Surgery, especially visceral surgery plays a crucial role in palliative care and is part of the \\ interdisciplinary treatment in advanced malignancies with reduced live expectancy.
}

Methods: An overview to document the up to date knowledge in the field of palliative surgery by reviewing and researching selective databases (Pubmed, Cochrane Library) and selected journals.

Results: Visceral surgery is a significant part of palliative care. Surgery is indicated in the emergency situation, in individual cases and when alternatives have been exhausted. Aim of the surgery is long-term and rapid control of symptoms, increasing the quality of life and decreasing the hospital stay.

Conclusion: The option of visceral surgery in advanced malignancies should be considered in each case individually due to the different tumor characteristics and localization. After critical reviewing, surgery can be indicated and must be integrated into a network of palliative care with available add-on therapies.

Keywords: Visceral surgery; Palliative; Advances malignancies; Oncology

\section{Introduction}

Palliative care is defined by the World Health Organization (WHO) as "an approach that improves the quality of life of patients and their families facing the problem associated with life threatening illness, through the prevention and relief of suffering by means of early identification and impeccable assessment and treatment of pain and other problems, physical, psychosocial and spiritual" [1].

Visceral surgery has an important role in this network of interdisciplinary and multimodal treatment options. The main goal in palliative care is to embed patients with advanced malignancies into a multimodal network of palliative treatment options to prevent tumor related complications. Many of those treatments include minimal/ non-invasive options such as endoscopic procedures, chemotherapy and radiotherapy which come along with lower morbidity rates compared to open surgery. However, in the case of tumor related complications that cannot be treated by alternative procedures, surgery plays a significant role in palliation to treat or prevent tumorrelated complications and to achieve a quick, long-lasting symptom control to improve and maintain the quality of life. The aim of this paper is to generate an overview of evidence based visceral surgical treatment options in palliative care by researching selective databases and current guidelines (Table 1).

\begin{tabular}{|l|l|}
\hline Entity & Palliative Treatment Option \\
\hline Esophageal Cancer & Palliative Esophagectomy \\
& Bypass: Gastric / Colonic interposition \\
\hline
\end{tabular}

\begin{tabular}{|l|l|}
\hline Gastric Cancer & $\begin{array}{l}\text { Palliative Gastrectomy } \\
\text { Bypass: Gastroenterostomy }\end{array}$ \\
\hline Pancreatic Cancer & $\begin{array}{l}\text { Palliative Pancreaticoduodenectomy } \\
\text { Bypass: Gastroenterostomy, Biliodigestive } \\
\text { Anastomosis }\end{array}$ \\
\hline Hepatobiliary Cancer & $\begin{array}{l}\text { Palliative Resection } \\
\text { Resection of Metastases } \\
\text { Bypass: } \\
\text { Cholecsystojejunostomy }\end{array}$ \\
\hline Colorectal Cancer & $\begin{array}{l}\text { Palliative Resection } \\
\text { Stomanostomy, } \\
\text { Bypass: Intestinointestinal Bypass }\end{array}$ \\
\hline $\begin{array}{l}\text { Peritoneal } \\
\text { Carcinomatosis }\end{array}$ & $\begin{array}{l}\text { Cytoreductive Surgery } \\
\text { HIPEC }\end{array}$ \\
\hline
\end{tabular}

Table 1: Treatment Options

\section{Esophageal Carcinoma}

More than $50 \%$ of patients diagnosed with an esopheageal carcinoma are incurable, as in $50 \%$ of the cases distant metastases and/or invasion into adjacent structures are present [2]. The 5-yearsurvival rate is less than $15 \%$ across all stages.

In most cases affected patients present with the leading symptom of dysphagia. Aim of the surgical intervention is to achieve an R0-status, since only an R0-status significantly increases the prognosis of the patient. 
Other treatment options for esophageal carcinoma, next to palliative resection which faded into the background due to increased mortality and morbidity rates are: bypass surgery via a gastric interposition with a transthoracic anastomosis or a colon interposition. However, the main indication for bypass surgery in the setting of esophageal cancer is the tracheoesophaglea/ bronchoesophageal fistula or when conservative treatment such as endoscopic stenting fails [3].

In addition, palliative resection of the esophagus is acceptable, if the surgery occurred in a primary curable setting. In this case a retrosternal bypass can be performed [4]. The main aim is to achieve symptom control such as dysphagia and aspiration.

In conclusion, palliative resection and bypass surgery play a secondary role in palliative treatment options of esophageal carcinoma. Only as an emergency operation and when alternative treatment options are exhausted surgery may be indicated. Due to high mortality and morbidity rates, alternatives such as upper endoscopy, PEG tube, brachytherapy as well as radio and chemotherapy in combination with endoscopic stenting play a bigger role in palliative care of esophageal carcinoma.

\section{Gastric Carcinoma}

The average survival rate for patients diagnosed with gastric cancer is less than one year. Around two thirds of affected individuals present in an advanced, incurable stage with symptoms such as dysphagia, discomfort/pain and upper gastrointestinal bleeding [5].

By definition, a palliative situation is present when a R0-resection is not possible, peritoneal carcinomatosis or distant metastases.

According to the current S3 guidelines for the surgical management of gastric cancer, a palliative resection in an asymptomatic, nonbleeding patient is not indicated. Resection is only indicated as the exception to the rule, dependent on nutritional state, age and alternative treatment options. The East German Gastric Cancer Study (2002) came to the same conclusion. They conducted a prospective, multicentric study evaluating 1139 patients between 01.01.2002 and 31.12.2003 in 80 surgical departments with a histological described gastric cancer. Out of 1031 operated patients, $n=305$ were palliative from which $n=63$ received an $\mathrm{R} 1$ resection and $\mathrm{n}=242$ a $\mathrm{R} 2$ resection. The study showed an increase in survival rate for patients who underwent palliative resection. Postoperative complications increased in concordance with increased surgical radicality. Due to its increased morbidity and mortality rate, palliative resection is only recommended in individual cases, for instance in a symptomatic outlet obstruction or cancer bleeding which cannot be treated by conservative/ interventional alternatives [6].

Kim et al. 2011 were able to show that patients with an isolated located metastases had a increased survival rate when the primary tumor and isolated metastases were resected as R0 compared to chemotherapy or $\mathrm{R} 1 / \mathrm{R} 2$ resection (survival rate of 28 months compared to 9 months) [7].

A bypass procedure, namely the gastroenterostomy, is a reasonable procedure for patients in poor general health or with an associated increased risk. More particular so, if a tumor is identified as nonresectable during an explorative laparotomy or laparoscopy. A gastroenterostomy can be done anterior, posterior, retrocolic or antecolic (Figure 1).

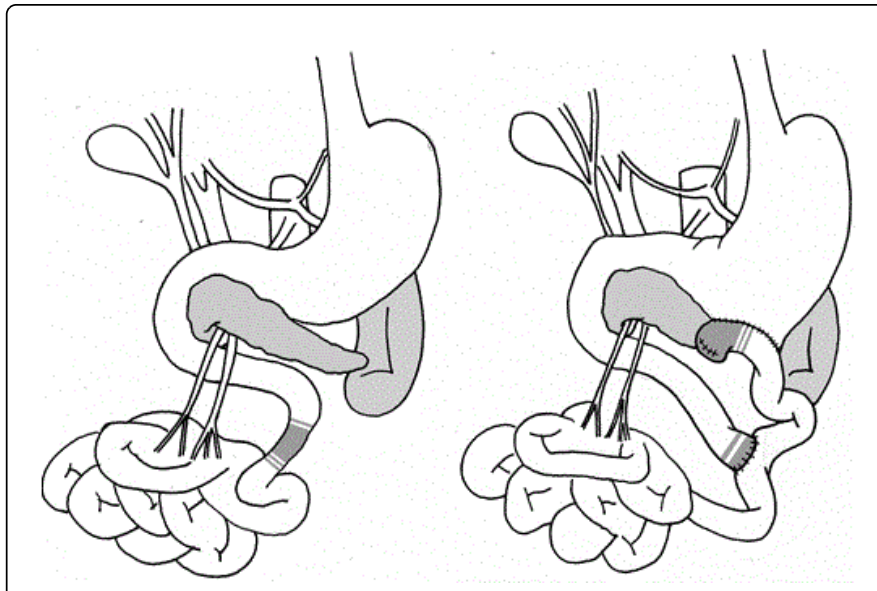

Figure 1: Gastroenterostomy

Palliative resection is not indicated in patients presenting with mere symptoms of stenosis. In this case, alternatives such as an endoscopic stenting, the above mentioned gastroenterostomy, a jejunal feeding tube or the palliative radiation are superior. The treatment option depends on the extent and severity of the symptoms and the localization of the cancer [5]. The immediate relieve of symptoms is a must and should be the aim of every treatment.

\section{Pancreatic Carcinoma}

Opposite to other cancers, pancreatic cancer does not present with a leading symptom. Symptoms can range from abdominal pain, back pain to jaundice, duodenal stenosis and malabsorption. The 5-yearsurvival rate is less than $5 \%$ with a median survival of four to eight months. Only $10-30 \%$ of the patients present with a surgically curable stage. Although progress of multimodal treatment concepts has been vast, the only chance to cure is a (R0)-resection of the cancer [8]. Here, preoperative diagnostics and surgical exploration play a crucial role. Reissfelder et al put emphasis on differentiating between two scenarios: "The scenario of intraoperative diagnosis of nonresectability and the scenario of preoperative diagnosed nonresectability".

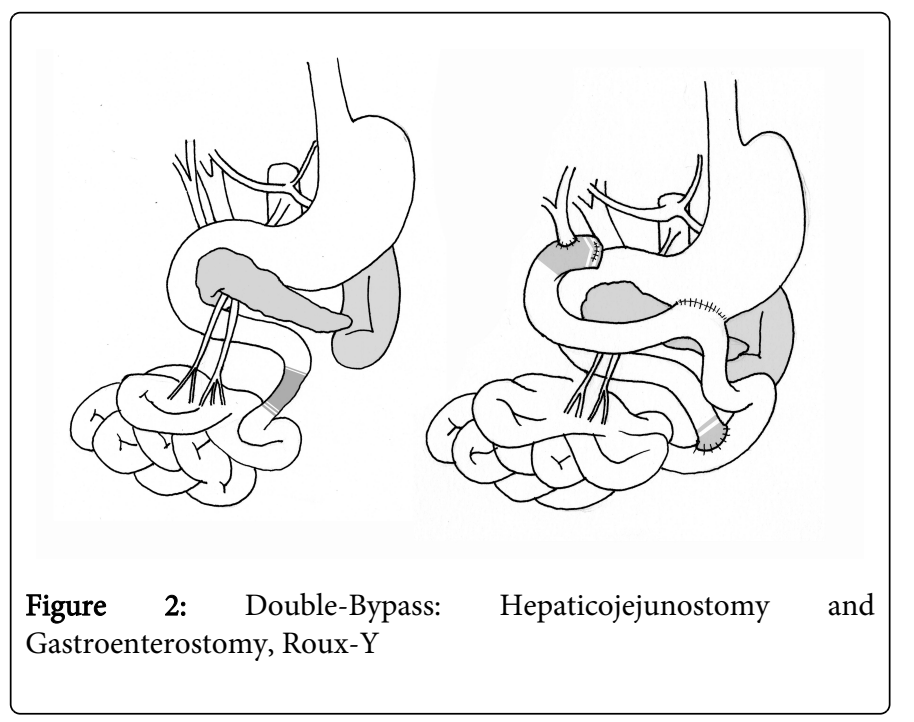


If non-resectability is diagnosed at the start of a surgical procedure due to metastases, a double bypass (gastroenterostomy, hepaticojejunostomy) is indicated (Figure 2). The second group would benefit from an endoscopical procedure since morbidity and mortality rates are lower. However, the long-term relieve is lower compared to the palliative double bypass [8].

Multivisceral resection is indicated, as long as a R0-resection can be guaranteed. Palliative resection proves to be a better treatment option when compared to alternative palliative treatments. Interaortocaval lymph node metastases (distant metastases) as well as the infiltration of the superior mesenteric vein or portal vein can be resected as R0 [9-10]. Aim of resection is complete removal of the tumor. The used procedure is dependent on the localization of the tumor. A current study is investigating whether a palliative pylorus-preserving pancreaticoduodenectomy with postoperative chemotherapy has a higher survival rate compared to primary chemotherapy in advanced pancreatic cancer [11].

\section{Hepatobiliary Carcinoma}

The surgical resection of malignancies in the hepatic system such as liver metastases, hepatocellular carcinoma (HCC), intrahepatic cholangiocarcinoma or Klatskin tumour, is in most cases the only curative treatment option. Complete tumour removal has most prognostic relevance [12].

HCC may originate in the setting of liver cirrhosis, viral hepatitis and alcohol. A HCC caused by liver cirrhosis increases the risk of recurrence which is attributed to the pattern of metastases and not to incomplete resection [13]. The median survival of an untreated HCC is between 3-8,3 months. Next to conservative treatment modalities such as transarterial chemoembolization (TACE), Radio Frequency Ablation (RFA) or systemic chemotherapy, secondary resectability after downstaging should be considered as an alternative. Here, 8-18\% of the primary non-resectable liver tumours were resectable after downstaging [14]. Hsu et al. described a much better result in the 1-, 3 -, and 5-year-survival rate after surgical resection compared to TACE with $82 \%$ vs $65 \%, 68 \%$ vs $29 \%$ and $46 \%$ vs $22 \%$ [15]

$60-70 \%$ of Klatskin-Tumours are diagnosed in an advanced stage. R0-resection is the aim of every resection. Analyzes showed that a complete removal was achieved more often in a right sighted liver resection (>70\%) compared to a left sighted liver resection $(33-50 \%)$ [14-17].

Regarding an extended right liver resection, an oncological radicality can be achieved through an increased safety margin due to given anatomical proportions [16]. In the setting of R1 and R2 resection, adjuvant chemotherapy led to an increased survival rate. When tumours are non-resectable, drainage of hepatic ducts is crucial. In this case, a hepaticojejunostomy or a cholezystojejunostomy (Figure 3) can be performed if an endoscopic approach is not possible [18].

The most common indication for liver resection is liver metastases. The most common primary tumor is colorectal cancer, breast cancer and gastric cancer. One differentiates between resectable and nonresectable metastases. The latter can be converted from a nonresectable stage to a resectable stage by neoadjuvant therapy. Bismuth et al. showed that $n=53$ out of $n=5530$ patients were converted from a primary non-resectable stage into a resectable one [19]. Further studies described a curative resection in up to $40 \%$ of treated patients $[20,21]$.
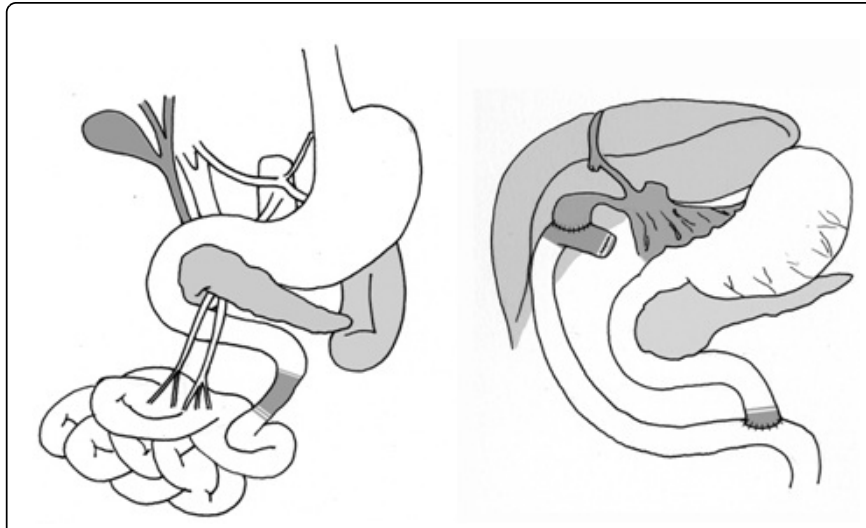

Figure 3: Cholezystojejunostomy

\section{Colorectal Carcinoma}

Colorectal cancer is the third most common cancer related cause of death worldwide [22]. The cancer specific 5-year-survival rate is $74,6 \%$ [23]. $20 \%$ of all patients present with distant metastases at diagnosis. $25 \%$ of the primary tumors are located in the rectum. Patients present with blood or mucous in the stool, diarrhea, constipation, bleeding and b-symptoms such as fever, night sweats, fatigue and weight loss.

In contrast to the above mentioned tumor entities, a R0-resection is possible despite distant metastases. Especially in the case of synchronic liver metastases, the resection of isolated liver metastases can increase the 5 -year-survival rate from $0-2 \%$ up to $28-37 \%$ [23,24]. Initially, only $10-20 \%$ fulfills the criteria for a curable resection in case of distant metastases. However, in another $10-15 \%$ of patients a secondary resection can take place after neoadjuvant therapy [25].

In addition, one was able to show that palliative resection has a better median survival rate compared to chemotherapy alone [26]. A palliative resection can also be planned as an elective surgery, since an emergency surgery in the case of bleeding or perforation increases the mortality rate over $30 \%$ [27].

A locally advanced rectal cancer can be converted into a curable stage by neoadjuvant radiochemotherapy [28]. In 33\% of patients receiving a total pelvic exenteration, an improved survival rate was noticed [29].

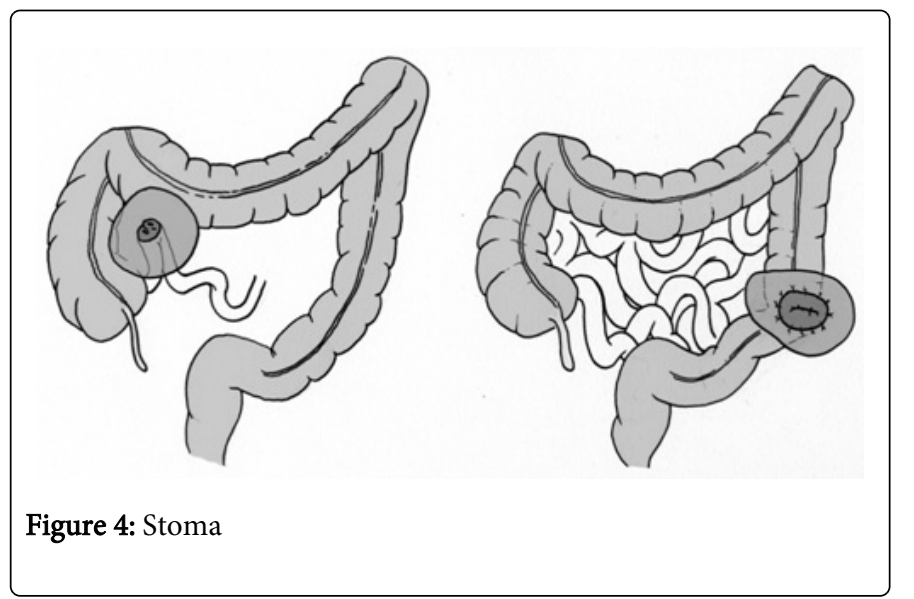


The option of an intestinointestinal bypass or a stoma (Figure 4) should be considered in patients who are in poor general health or those undergoing neoadjuvant therapies. Here, the prevention of a mechanical ileus caused by tumor stenosis is in the foreground.

Palliative resection is indicated in all symptomatic (stenosis) patients that cannot be treated conservatively. An intestinointestinal bypass is preferred over a colostoma or protective ileostoma as only the bypass allows colonic continuity [30].

\section{Peritoneal Carcinomatosis}

The implantation and growth of tumor cells in the peritoneum leads to peritoneal carcinomatosis. $8 \%$ of all tumor entities present with peritoneal carcinomatosis at diagnosis [31]. Until recently one presumed that peritoneal carcinomatosis is a limited disease. In 1980 Spratt et al. first described the hyperthermaic intraperitoneal chemotherapy (HIPEC) as an alternative treatment option, given that all peritoneal lumps have been resected [32,33].

Harmon et al. described the "Peritoneal Cancer Index" (PCI) [34]. Here, the abdomen and pelvis are divided into 13 regions. For every region 0 (no lumps) -3 points (lumps $>5 \mathrm{~cm}$ ) can be given.

A combination therapy between HIPEC and cytoreductive surgery showed a median survival rate of 22,3 months compared to 12,6 months in patients treated with systemic chemotherapy with or without palliative resection [35].

The mortality rate for gastric cancer with peritoneal metastases is $100 \%$ (32). Sugarbaker et al. showed that a combination of gastrectomy, cytoreductive surgery and HIPEC constitute a sufficient treatment option for this patient group [36]. An increased survival was also described in patients with peritoneal sarcomatosis $[37,38]$.

Verwaal et al. (2003) showed that cytoreduction and hyperthermic intraperitoneal chemotherapy increased the median survival up to 22.3 months compared to 12.6 months (standard therapy) in the treatment of patients with peritoneal carcinomatosis of colorectal cancer.

Regarding peritoneal carcinomatosis of ovarian cancer, studies have shown that cytoreductive surgery in combination with hyperthermic intraperitoneal chemotherapy increased the overall survival rate [39]. Fagotti et al. (2011) carried out a large single-institutional series showing a median disease free and overall survival of 24 and 38 months respectively.

HIPEC with prior peritonectomy can be used in certain patients groups leading to better symptom control, improved survival rate and control of the tumor. In April 2011 the HIPEC registry was started with a trial of 100 patients from six clinics. Up to date the registry counts 1407 patients [40].

\section{Conclusion}

Visceral surgery plays a significant part in the interdisciplinary treatment of advanced malignancies. The decision to operate should be made individually, dependent on tumor characteristics and localization. In many instances tumor related complications of the gastrointestinal tract such as bleeding and stenosis can be managed by less invasive options such as endoscopic procedures. However, if complications cannot be managed conservatively or in an emergency situation, surgery is indicated and the only option. Moreover, palliative resection is indicated as cytoredutive surgery and therefore increasing long-time survival due to decreasing tumor size and its related production of immunosuppressive cytokines. Aim of palliative resection is the quick and long-term control of symptoms, increasing and maintaining the quality of live as well as reducing the hospital stay.

\section{References}

1. Palliativ Portal.

2. Beller S, Schlag PM (2006) [Significance of palliative resection of gastrointestinal tumors]. Chirurg 77: 219-225.

3. Mannell A, Becker PJ, Nissenbaum M (1988) Bypass surgery for unresectable oesophageal cancer: early and late results in 124 cases. $\mathrm{Br} \mathrm{J}$ Surg 75: 283-286.

4. Sharma D, De Silva J, Saxena A, Agrawal S, Raina VK (2000) Incontinuity fundic bypass for palliation in unresectable carcinoma of the oesophagus: a previously unreported procedure. Dig Surg 17: 303-306.

5. Meyer HJ, Hölscher AH, Lordick F, Messmann H, Mönig S, et al. (2012) [Current S3 guidelines on surgical treatment of gastric carcinoma]. Chirurg 83: 31-37.

6. Gastinger I, Ebeling U, Meyer L, Meyer F, Schmidt U, et al. (2012) [Advanced gastric cancer. Are there still indications for palliative surgical interventions?]. Chirurg 83: 472-479.

7. Kim KH, Lee KW, Baek SK, Chang HJ, Kim YJ, et al. (2011) Survival benefit of gastrectomy \pm metastasectomy in patients with metastatic gastric cancer receiving chemotherapy. Gastric Cancer 14: 130-138.

8. Reissfelder C, Koch M, Büchler MW, Weitz J (2007) [Pancreatic carcinoma]. Chirurg 78: 1059-1071.

9. Tseng JF, Raut CP, Lee JE, Pisters PW, Vauthey JN, et al. (2004) Pancreaticoduodenectomy with vascular resection: margin status and survival duration. J Gastrointest Surg 8: 935-949.

10. Adler G, Seufferlein T, Bischoff SC, Brambs HJ, Feuerbach S, et al. (2007) [S3-Guidelines "Exocrine pancreatic cancer" 2007]. Z Gastroenterol 45: 487-523.

11. Palliative pyloruserhaltende Pankreaskopfresektion mit postoperativer Chemotherapie versus primärer Chemotherapie bei fortgeschirttenem Pankreaskarzinom, offene, prospektive randomisierte Phase III Studie.

12. Giuliani F, Colucci G (2009) Treatment of hepatocellular carcinoma. Oncology 77 Suppl 1: 43-49.

13. Kolb A, Kleeff J, Friess H, Büchler MW (2007) [The effect of R1 resection in the hepatobiliary pancreatic system]. Chirurg 78: 802-809.

14. Lau WY, Lai EC (2007) Salvage surgery following downstaging of unresectable hepatocellular carcinoma--a strategy to increase resectability. Ann Surg Oncol 14: 3301-3309.

15. Hsu CY, Hsia CY, Huang YH, Chien-Wei Su, Han-Chieh Lin. et al. (2012) Comparison of surgical resection and transarterial chemoembolization for hepatocellular carcinoma beyond the Milan criteria: a propensity score analysis. Annals of surgical oncology. 19: 842-849.

16. Seehofer D, Kamphues C, Neuhaus P (2012) [Resection of Klatskin tumors]. Chirurg 83: 221-228.

17. Miyazaki M1, Ito H, Nakagawa K, Ambiru S, Shimizu H, et al. (1998) Aggressive surgical approaches to hilar cholangiocarcinoma: hepatic or local resection? Surgery 123: 131-136.

18. Schlitt HJ, Weimann A, Klempnauer J, Oldhafer KJ, Nashan B, et al. (1999) Peripheral hepatojejunostomy as palliative treatment for irresectable malignant tumors of the liver hilum. Ann Surg 229: 181-186.

19. Bismuth H, Adam R, Levi F, Farabos C, Waechter F, et al. (1996) Resection of nonresectable liver metastases from colorectal cancer after neoadjuvant chemotherapy. Ann Surg 224: 509-520.

20. Barone C, Nuzzo G, Cassano A, Basso M, Schinzari G, et al. (2007) Final analysis of colorectal cancer patients treated with irinotecan and 5fluorouracil plus folinic acid neoadjuvant chemotherapy for unresectable liver metastases. Br J Cancer 97: 1035-1039.

21. Folprecht G, Gruenberger T, Bechstein WO, Raab HR, Lordick F. et al. (2010) Tumour response and secondary resectability of colorectal liver 
Citation: $\quad$ El-Sourani N, Troja A, Contin P, Raab HR, Antolovic D (2014) Visceral Surgery: Treatment Options in Palliative Care. J Integr Oncol 3:

Page 5 of 5

metastases following neoadjuvant chemotherapy with cetuximab: the CELIM randomised phase 2 trial. The lancet oncology. 11: 38-47.

22. Globocon (2008) Cancer Incidence and Mortality Worldwide. World Health Organization.

23. Schmiegel W, Pox C, Reinacher-Schick A, Adler G, Arnold D, et al (2010) S3 guidelines for colorectal carcinoma: results of an evidencebased consensus conference on February 6/7, 2004 and June 8/9, 2007 (for the topics IV, VI and VII). Z Gastroenterol 48: 65-136.

24. Fong Y, Fortner J, Sun RL, Brennan MF, Blumgart LH (1999) Clinical score for predicting recurrence after hepatic resection for metastatic colorectal cancer: analysis of 1001 consecutive cases. Ann Surg 230: 309-318.

25. Adam R, Avisar E, Ariche A, Giachetti S, Azoulay D, et al. (2001) Fiveyear survival following hepatic resection after neoadjuvant therapy for nonresectable colorectal. Ann Surg Oncol 8: 347-353.

26. Crane CH, Janjan NA, Abbruzzese JL, Curley S, Vauthey J, et al. (2001) Effective pelvic symptom control using initial chemoradiation without colostomy in metastatic rectal cancer. Int J Radiat Oncol Biol Phys 49: 107-116.

27. Meyer F, Marusch F, Koch A, Meyer L, Führer S, et al. (2004) Emergency operation in carcinomas of the left colon: value of Hartmann's procedure. Tech Coloproctol 8 Suppl 1: s226-229.

28. Braendengen M, Tveit KM, Ake Berglund, Elke Birkemeyer, Gunilla Frykholm, et al. (2008) Randomized phase III study comparing preoperative radiotherapy with chemotradiotherapy in nonresectable rectal cancer. Journal of clinical oncology 26: 3687-3694.

29. Govindarajan A, Coburn NG, Kiss A, Rabeneck L, Smith AJ, et al. (2006) Population-based assessment of the surgical management of locally advanced colorectal cancer. J Natl Cancer Inst 98: 1474-1481.

30. Wojtyczka A, Moesta T, Kuntz C, Lehnert T (2006) [Palliative bypass surgery]. Chirurg 77: 210-218.
31. Esquivel J, Elias D, Baratti D, Kusamura S, Deraco M (2008) Consensus statement on the loco regional treatment of colorectal cancer with peritoneal dissemination. J Surg Oncol 98: 263-267.

32. Basisprotokoll für ein multimodales chirurgisches Therapiekonzept zur Behandlung von Patienten mit Peritonealcarcinose mittels Peritonektomie/Multivisze-ralresektion und hyperthermer intraperitonealer Chemotherapie. Deutsche Gesellschaft für Allgemeinund Viszeralchirurgie.

33. Spratt JS, Adcock RA, Muskovin M, Sherrill W, McKeown J (1980) Clinical delivery system for intraperitoneal hyperthermic chemotherapy. Cancer Res 40: 256-260.

34. Harmon RL, Sugarbaker PH (2005) Prognostic indicators in peritoneal carcinomatosis from gastrointestinal cancer. Int Semin Surg Oncol 2: 3 .

35. Verwaal VJ, et al. Randomized trial of cytroreduction and hyperthermic intraperitoneal chemotherapy versus systemic chemotherapy and palliative surgery in patients with peritoneal carcinomatosis of colorectal cancer.

36. Sugarbaker PH, Yonemura Y (2000) Clinical pathway for the management of resectable gastric cancer with peritoneal seeding: best palliation with a ray of hope for cure. Oncology 58: 96-107.

37. Berthet B, Sugarbaker TA, Chang D, Sugarbaker PH (1999) Quantitative methodologies for selection of patients with recurrent abdominopelvic sarcoma for treatment. Eur J Cancer 35: 413-419.

38. Eilber FC, Rosen G, Forscher C, Nelson SD, Dorey FJ, et al. (1999) Surgical resection and intraperitoneal chemotherapy for recurrent abdominal sarcomas. Ann Surg Oncol 6: 645-650.

39. Markman M (1986) Intraperitoneal antineoplastic agents for tumors principally confined to the peritoneal cavity. Cancer Treat Rev 13: 219-242.

40. Deutsche Gesellschaft für Allgemein- und Viszeralchirurgie (2011) Start of HIPEC register of the CAO-V. 